This item was submitted to Loughborough's Research Repository by the author.

Items in Figshare are protected by copyright, with all rights reserved, unless otherwise indicated.

\title{
Investigation of reciprocating conformal contact of piston skirt-to-surface modified cylinder liner in high performance
}

PLEASE CITE THE PUBLISHED VERSION

http://dx.doi.org/10.1243/095440605X32147

PUBLISHER

Professional Engineering Publishing / @ IMECHE

VERSION

VoR (Version of Record)

LICENCE

CC BY-NC-ND 4.0

REPOSITORY RECORD

Balakrishnan, Sashi, S.J. Howell-Smith, and Homer Rahnejat. 2019. "Investigation of Reciprocating Conformal Contact of Piston Skirt-to-surface Modified Cylinder Liner in High Performance". figshare.

https://hdl.handle.net/2134/4821. 
This item was submitted to Loughborough's Institutional Repository (https://dspace.lboro.ac.uk/) by the author and is made available under the following Creative Commons Licence conditions.

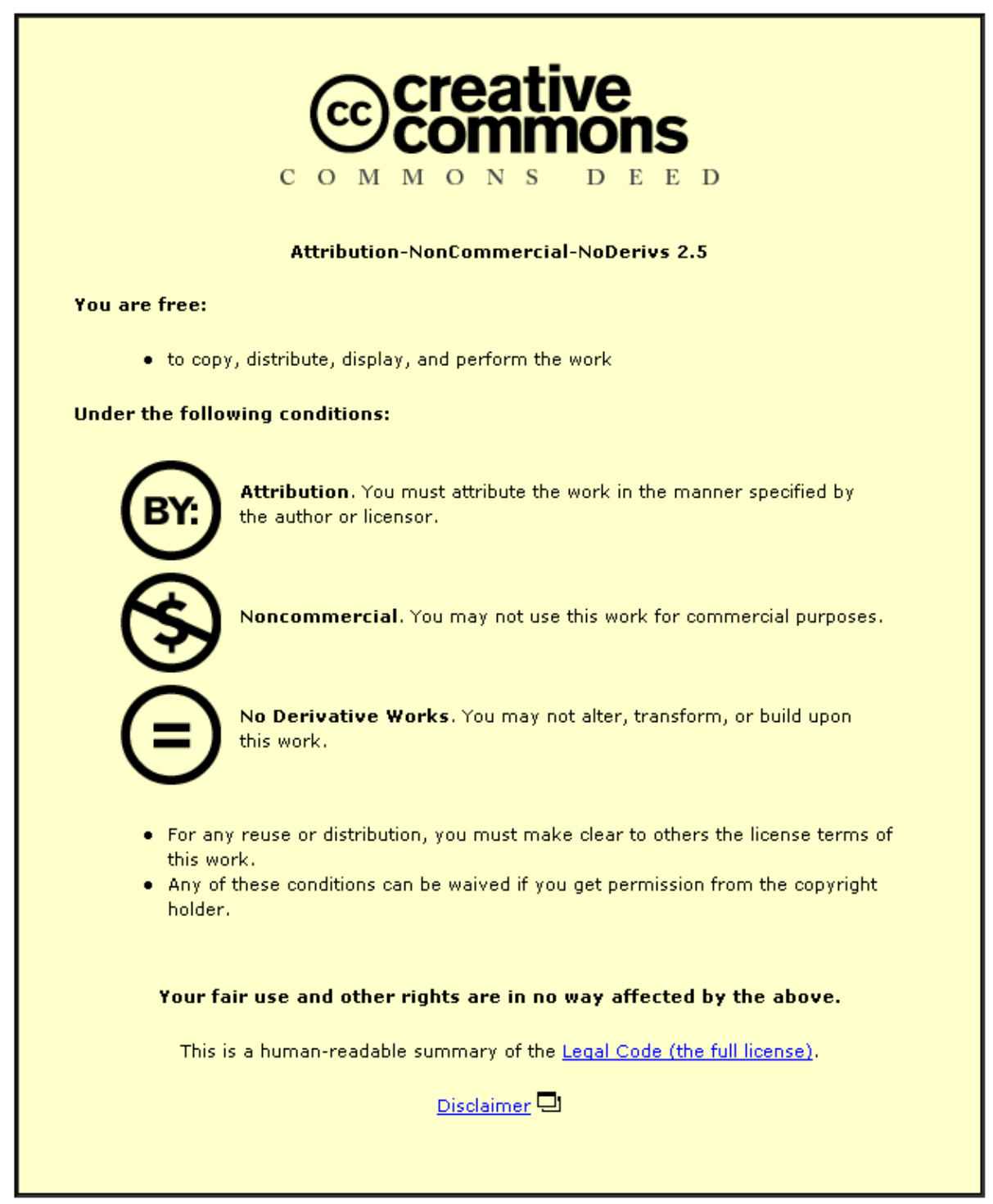

For the full text of this licence, please go to: http://creativecommons.org/licenses/by-nc-nd/2.5/ 


\title{
Investigation of reciprocating conformal contact of piston skirt-to-surface modified cylinder liner in high performance engines
}

S Balakrishnan ${ }^{1}$, S Howell-Smith ${ }^{2}$, and H Rahnejat ${ }^{1 *}$

${ }^{1}$ Wolfson School of Mechanical and Manufacturing Engineering, Loughborough University, Loughborough, UK

${ }^{2}$ Perfect Bore Motorsport Limited, Mayfield Industrial Park, Andover, Hampshire

The manuscript was received on 1 December 2004 and was accepted after revision for publication on 15 August 2005.

DOI: 10.1243/095440605X32147

\begin{abstract}
The article presents detailed analysis of the conforming contact between a piston and cylinder liner in a high-speed racing engine under extreme operating conditions owing to high loads and operating speeds in excess of $19000 \mathrm{r} / \mathrm{min}$, resulting in a high sliding velocity of $42 \mathrm{~m} / \mathrm{s}$. The analysis indicates contact forces generated in the order of $2.5 \mathrm{kN}$. The contribution due to fluid film lubrication is found to reside in iso-viscous rigid or elastic regimes of lubrication, which is insufficient to form a coherent lubricant film during some parts of the cycle, such as at top-dead-centre (TDC). The article shows that at combustion, 95 per cent of the contact can remain in boundary or mixed regimes of lubrication. Piston skirt surface modification features are used in conjunction with an electrolytically applied composite coating, $\mathrm{Ni}[\mathrm{SiC}] \mathrm{p}$ to produce advanced cylinder liners to remedy the situation. Detailed numerical analysis shows that significant improvement is achieved in the regime of lubrication condition.
\end{abstract}

Keywords: piston-to-cylinder bore contact, surface modification, high performance engines

\section{INTRODUCTION}

The use of light-weight components in engine is currently a common practice. This is also the case for a piston, to reduce inertial imbalance [1]. The prime user of such technology is the motorsport sector, purely owing to less restrictive financial constraints when compared with that of the mass manufacturing automobile sector. One common trend in motorsport engine development is weight reduction, mainly in the reciprocating components [2].

The piston skirt experiences high side forces and, therefore, sufficient lubrication is critical to separate the piston skirt from the cylinder liner. Piston skirts for such applications are generally modified to trap lubricant with the aim of ensuring a sufficient film of lubricant in the contact to prevent the two bodies from coming into direct contact [3]. However, this practice has been carried out in an empirical

*Corresponding author: Wolfson School of Mechanical and Manufacturing Engineering, University of Loughborough, Loughborough, Leicestershire LE11 3TU, UK. manner, on the basis of repetitive engine testing results.

Therefore, a fundamental understanding through detailed tribodynamic analysis of the problem is necessary. Many other investigations have also been reported [3-6]. The emphasis in the current investigation is on the detailed analysis of elastic deformation of contiguous bodies, geometrical profile of mating members and in particular, the effect of surface features should be considered, to retain a coherent film. Therefore, this article outlines the optimization of advanced technology piston liner interaction in high-speed engines.

\section{METHOD}

\subsection{Elastic film shape}

The liner insert of the engine investigated here is made of electrolytically coated aluminium alloy, whereas the pistons are made out of a different high-grade aluminium. The cylinder bore has typically a nominal circular profile with a radius of 

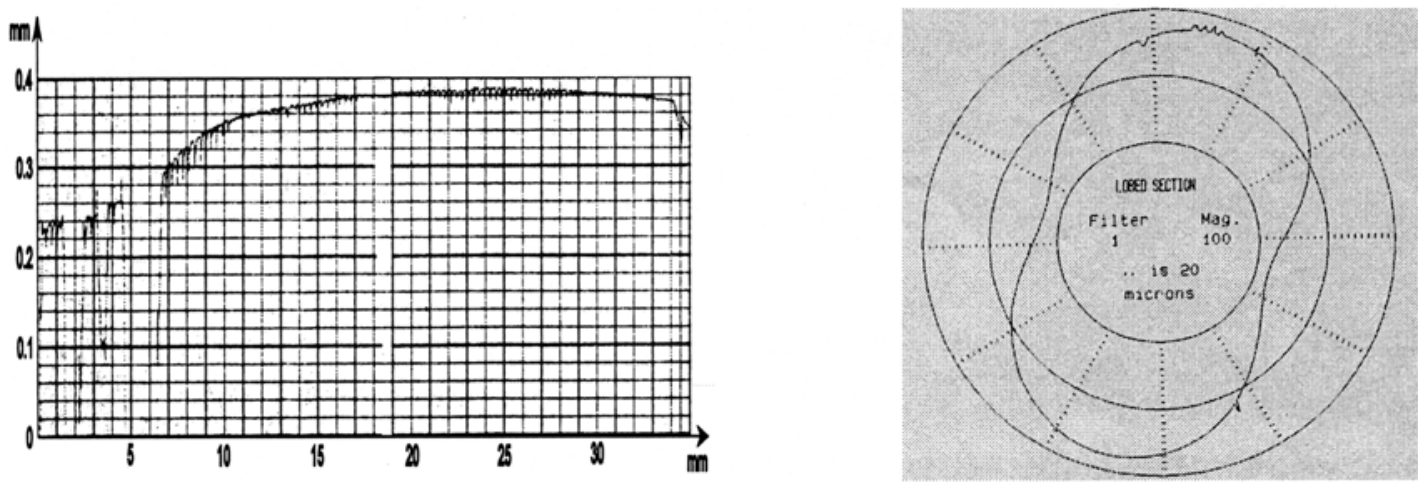

Fig. 1 Piston skirt profile

$48 \mathrm{~mm}$, when running under no combustion load (achieved by employing specialist technique to overcome mechanical and thermal strains). The piston skirt profile varies along the piston length as shown in Fig. 1(a), whereas the piston skirt is approximately elliptical in the circumferential direction as shown in Fig. 1(b). The profile variation is necessary to counteract the effects of thermal expansion because of varying temperature gradient along the skirt.

The length of piston skirt in nominal contact with the bore is approximately $17 \mathrm{~mm}$. The longitudinal profile of the piston skirt incorporates relief radii at its axial extremities, to both act as a wedge to encourage lubricant entrainment into the contact, and to discourage generation of edge stress discontinuity [7].

The piston skirt axial profile is asymmetrical, as shown in Fig. 1(b). The bottom of the skirt features a truncated radius of $0.03 \mathrm{~mm}$ and the top of the skirt features a chamfered runoff of $15^{\circ}$. The truncated radius and the chamfer create the wedge effect for lubricant entrainment as the piston traverses in the bore. The piston profile can be expressed as

$$
h_{i, j}=c+s_{i, j} \tan \beta+\delta_{i, j}
$$

This provides the film shape at any location in the contact (axial and circumferential), when the footprint is viewed as unwrapped with a mesh of nodal points: $i, j$. The tilt angle $\beta$ is in the thrust, anti-thrust plane.

\subsection{Contact deformation}

Deflection must be obtained at any location $i, j$ in the contact domain, and to be used in equation (1). This is obtained by the solution of general contact elasticity integral as

$$
\delta_{i, j}=\frac{2}{\pi E^{\prime}} \int_{-\mathrm{a}}^{\mathrm{a}} \int_{-\mathrm{b}}^{\mathrm{b}} \frac{p_{i, j} \mathrm{~d} x_{1} \mathrm{~d} y_{1}}{\left\{\left(x-x_{1}\right)^{2}+\left(y-y_{1}\right)^{2}\right\}^{1 / 2}}
$$

The deformation obtained is because of pressures within the contact area. The current analysis does not take into account the global (bending) deformation of the piston skirt caused by thermo-elastic effect. In practice, this can play a major role (discussed later).

\subsection{Reynolds equation}

The generated pressure distribution is obtained from the solution of Reynolds' hydrodynamic equation. For the contact described here the two-dimensional Reynolds' equation for sliding motion, taking place in the $x$-direction (being along the axial direction of the cylinder bore) in dimensional form is given as:

$$
\begin{aligned}
& \frac{\partial}{\partial x}\left(\frac{\rho h^{3}}{\eta} \frac{\partial p}{\partial x}\right)+\frac{\partial}{\partial y}\left(\frac{\rho h^{3}}{\eta} \frac{\partial p}{\partial y}\right) \\
& =12\left(u_{\mathrm{AV}} \frac{\partial}{\partial x}(\rho h)+\frac{\partial}{\partial t}(\rho h)\right)
\end{aligned}
$$

The Couette flow term on the right-hand side of the equation is due to the relative sliding motion of the piston with respect to the cylinder liner. The speed of lubricant entrainment is at $u_{\mathrm{AV}}=1 / 2 \dot{x}$. The second term on the right-hand side of equation gives the rate of change of elastic film shape. This is known as the squeeze film term.

\subsection{Boundary conditions}

There are two exit boundary conditions employed to limit the solution domain. First, pressure elements at the edges of the computational boundary are set to zero. Second, to avoid the generation of negative pressures in the fluid film, at the cavitation boundary, the Reynolds' condition: $P=\partial P / \partial \bar{x}=\partial P / \partial \bar{y}=0$ is employed. This condition prevails by setting any value of $P$ to zero every time a negative pressure value is encountered during the iteration procedure. The inlet boundary is assumed to be fully flooded. 
Owing to a sufficient supply of lubricant, this assumption is deemed acceptable in the downstroke sense of the piston. In practice, during the upstroke, the inlet condition depends on the fill ratio.

\subsection{Lubricant rheology}

Lubricant viscosity-pressure dependence is given by Barus $[\mathbf{8}]$ as

$$
\eta=\eta_{0} e^{\alpha p}
$$

Lubricant density variation with pressure is given by Dowson and Higginson [9] as

$$
\bar{\rho}=1+\frac{0.6 p}{1+1.7 p}
$$

\section{METHOD OF SOLUTION}

The Newton-Raphson method is applied to the solution of Reynolds' equation in the following numerical form

$$
\sum_{l=2}^{m y-1} \sum_{k=2}^{m x-1} J_{k, l}^{i, j} \Delta P_{k, l}=-F_{i, j}^{\mathrm{R}}
$$

where, $F_{i, j}^{\mathrm{R}}$ is the Reynolds' equation and is referred to as the residual term. The Jacobian matrix is a multi-index quantity (comprising all the nodal locations: $i, j$ in the contact), given in terms of the residual derivatives as

$$
J_{k, l}^{i, j}=\frac{\partial F_{i, j}}{\partial P_{k, l}}
$$

The Jacobian matrix is a tridiagonal matrix. Using the Gauss-Seidel iteration method, the system state equation can be written as

$$
\Delta P_{k, l}^{n}=\frac{\begin{array}{c}
\left(-F_{i, j}-J_{k-1, l}^{i, j} \Delta P_{k-1, l}^{n}-J_{k+1, l}^{i, j} \Delta P_{k+1, l}^{n-1}\right. \\
\left.-J_{k, l-1}^{i, j} \Delta P_{k, l-1}^{n}-J_{k, l+1}^{i, j} \Delta P_{k, l+1}^{n-1}\right)
\end{array}}{J_{k, l}^{i, j}}
$$

where $n$ is the iteration counter in the previous recursive equation. For the reason of good numerical stability an under-relaxation factor is employed to update the predicted pressures according to

$$
P_{i, j}^{n}=P_{i . j}^{n-1}+\Omega \Delta P_{i, j}^{n}
$$

where $\Omega$ is the under-relaxation factor, typically 0.1 , chosen under the reported conditions in this article.

\subsection{Convergence criteria}

There are two convergence criteria. First, pressure convergence is sought according to the following

$$
\left[\frac{\sum_{i} \sum_{j}\left(P_{i, j}^{n}-P_{i, j}^{n-1}\right)^{2}}{N}\right]^{0.5} \leqslant 10^{-4}
$$

where $N=n_{x} n_{y}$

If the previous condition does not satisfy the iteration index, $n$ is updated and the whole aforementioned procedure is repeated (equation (9)). The convergence criterion on load balance (equating the contact load determined by kinetic balance of forces acting on the piston with the integrated pressure distribution under quasi-static conditions) is given as

$$
\left|\iint P(\bar{x}, \bar{y}) \mathrm{d} \bar{x} \mathrm{~d} \bar{y}-W\right| \leqslant 10^{-4}
$$

If the previous condition is unsatisfied, the lubricant film thickness is adjusted and the earlier procedure is repeated. This is carried out using the following relationship

$$
\bar{h}=\bar{c}+\zeta\left[W-\iint P \mathrm{~d} \bar{x} \mathrm{~d} \bar{y}\right]
$$

where $\zeta$ is a damping parameter, chosen in the range: $0.01 \rightarrow 0.08$.

\section{SIMULATION CONDITION}

The study is carried out for a typical cylinder of a 10-cylinder 4-stroke engine, with excess of $920 \mathrm{Bhp}$. The combustion curve, shown in Fig. 2, is measured using a Kistler pressure sensor, with the combustion occurring $11^{\circ}-13^{\circ}$ past the TDC, as measured in terms of crank-angle rotation. This represents an aligned conforming profile of the skirt (the undeformed profile of the piston as seen from the bore with no piston tilt) against the cylinder liner. The contact domain is quite large in many instances and to obtain convergence and realistic pressure distributions, it is necessary to use as refined a computational mesh as possible.

The speed of piston in this engine reaches a maximum of $42 \mathrm{~m} / \mathrm{s}$. The entraining motion ceases at TDC and bottom-dead-centre (BDC) momentarily, and the lubricant is retained in these instances by entrapment, squeeze film motion (because of deformation of contacting bodies), and rapid replenishment because of the short-lived stop time (restart of entraining motion). The engine has a stroke of 


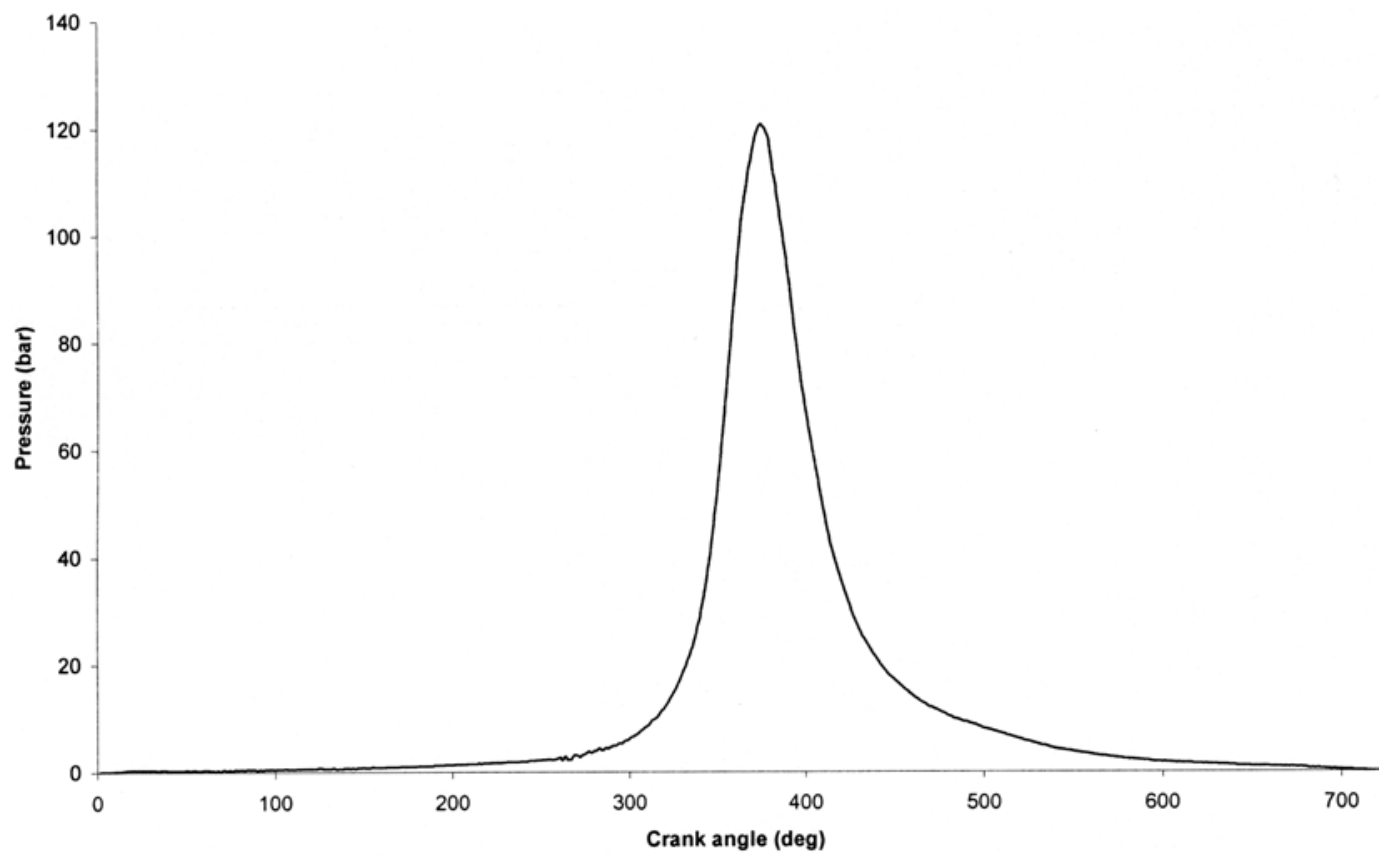

Fig. 2 Cylinder pressure

$41.4 \mathrm{~mm}$, whereas the connecting rod length is $102 \mathrm{~mm}$.

\section{RESULTS AND DISCUSSION}

A position of interest in any tribodynamic analysis of piston skirt or ring-pack-to-cylinder liner contact is at peak in-cylinder pressure, which occurs after the air-fuel mixture is ignited. This position, as already described previously occurs at approximately $13^{\circ}$ past the position of TDC. The maximum combustion at this location lessens the effect of piston slapping action at TDC. The combustion pressure rises dramatically just prior to this location, resulting in corresponding high contact forces. At the same time the velocity of the piston relative to the stationary liner, and consequently the speed of entraining motion of the lubricant is still comparatively low in its downward direction. The combination of high contact load and low speed of entraining motion usually translates to some of the worst tribological conditions.

The downward sliding velocity is designated to be positive, and is $11 \mathrm{~m} / \mathrm{s}$ at this location. The piston is misaligned by $0.1^{\circ}$ with respect to the vertical axis of the cylinder bore, and the contact force is $2.5 \mathrm{kN}$. Note that the contact force and the tilt angle have been obtained by a dynamic analysis, reported elsewhere [7]. The analysis here is confined to tribological issues.

Figure 3 shows the three-dimensional predicted pressure distribution. The contact area is extended circumferentially over approximately a $\pi$-film and in the axial direction over a length of approximately $17 \mathrm{~mm}$. Note the edge pressure spikes, which are reminiscent of edge stress discontinuities in counterformal contacts, such as a roller to a flat semi-infinite elastic half-space (see $[\mathbf{1 0}, \mathbf{1 1}]$ for example). The abrupt change in the axial profile of the piston skirt in the vicinity of its leading and trailing edges gives rise to these pressure spikes. The relief radii or chamfers are used precisely for the reason of reducing these edge effects. Any tilt of the piston accentuates the problem at the skirt end penetrating into the liner, while relieving the high pressures at the lifted end. This has also been shown in the same references. It should be noted that under lubricated conditions, the pressure spikes increase from their elastostatic levels for the same load, although mid-span contact pressures reduce in magnitude.

The three-dimensional pressure distribution in Fig. 3 can be regarded as a good visualization tool. A quantitative description of the generated contact pressures can be provided by an isobar plot, which is a two-dimensional representation over the pressure generating domain. It depicts regions of constant pressure or in other words isobars (see Fig. 4). The direction of entraining motion is from left to right in this figure, which corresponds to the downstroke sense of the piston, with the inlet being on the bottom side of the skirt. Unlike the normal lubricated conjunctions, the maximum pressure is on the inlet side owing to the more abrupt profile here than at the exit. The regions of high pressures occur over the flat region of the piston skirt axial profile. This 


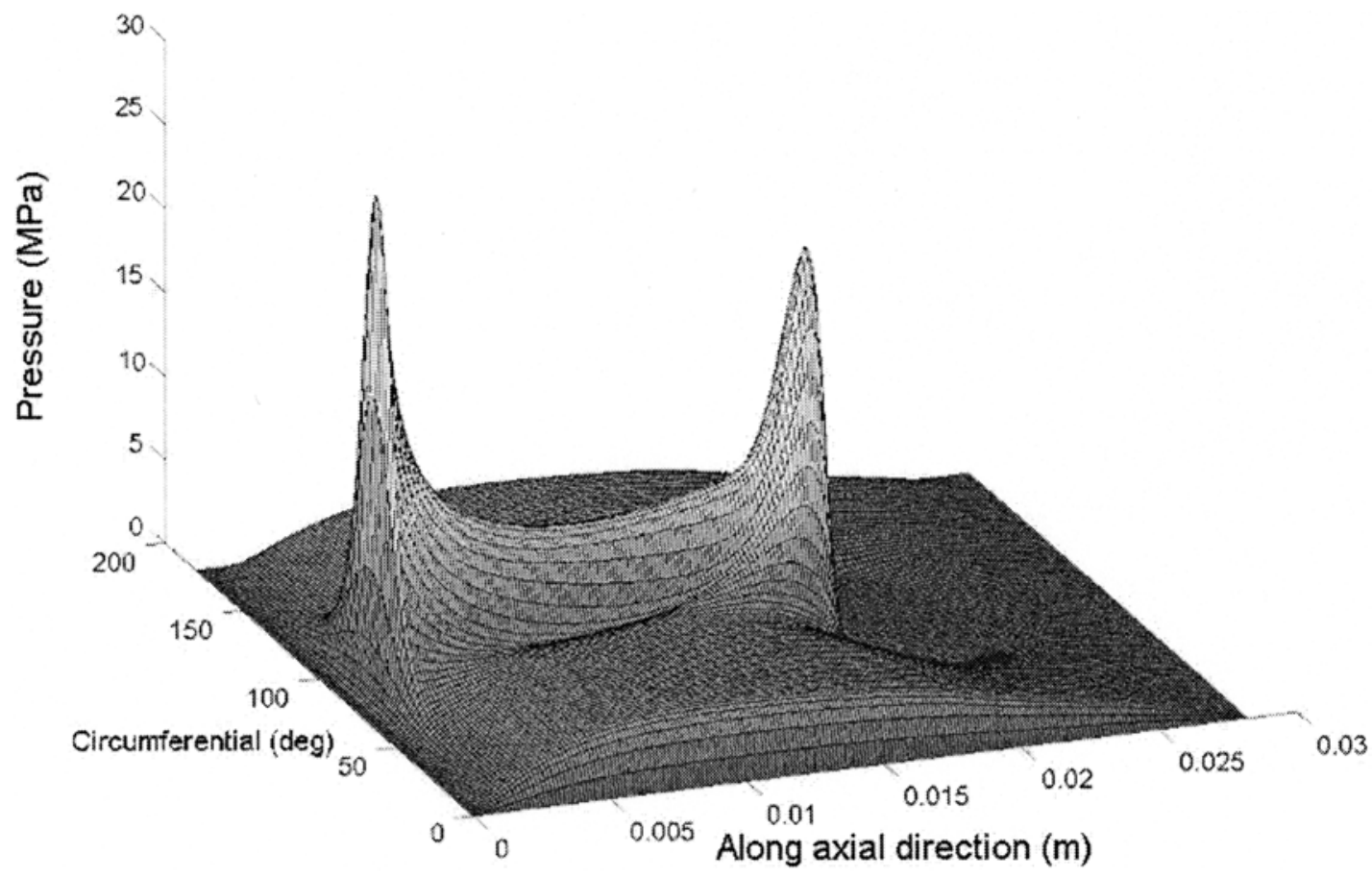

Fig. 3 Three-dimensional pressure distribution at maximum combustion pressure (entraining direction from left to right along the axial direction)

is indicated by the islands of pressure spikes to either sides of the contact and along the centreline of the contact in the circumferential direction. Note that the asymmetry in the axial pressure distribution is due to the differences between the relief radii at the top and the bottom of the skirt, as well as the misalignment of the contact. The maximum pressures occur on the left-hand side of the figure, which correspond to the bottom of the piston skirt, and in the vicinity and prior to the commencement of the relief radius. The maximum pressure value is 29.2 MPa. The corresponding maximum pressure isobar on the other end of the skirt is in a similar location with a value of $22.9 \mathrm{MPa}$.

Because of piston ovality and the degree of its conformance to the cylinder bore, the region of high pressures is concentrated in the domain $66^{\circ}-114^{\circ}$. Figures 5 and 6 show two-dimensional pressure profiles for the inlet and the outlet regions of the contact in the circumferential direction, respectively.

The corresponding minimum film thickness values in these contact cross-sections occur in the vicinity of the maximum pressures, with the lowest film thickness of $1.97 \mu \mathrm{m}$. The minimum film thickness occurs here, because of the existence of pressure spikes, inhibiting the flow of lubricant into this region.

Figures 7 and 8 show the axial pressure distribution and the corresponding lubricant film thickness through the centre of the contact. Note the pressure spikes at the extremities of the contact, which occur in the vicinity of sudden change from the flat profile to that of the relief radii. The continuity or smoothness of this change ensures a reduction in the magnitude of pressure 'pips'. This problem has been tackled in higher pressure concentrated counterformal lubricated conjunctions such as in rolling element and tapered roller bearings by edge blending or crowing of rollers $[\mathbf{1 0}, \mathbf{1 2}]$. The same approach is undertaken in the case of piston skirts, but in a rather arbitrary manner.

In high-speed pistons, a similar approach is employed by the introduction of a large crown radius covering the entire length of skirt, known as barrelling with crowned edges. The flow of the lubricant can be inhibited into these high-pressure regions (resulting in corresponding dips in the oil film thickness as shown in Fig. 8). In practice, with thermo-elastic distortion (not included in this analysis) the clearance between the piston skirt and the cylinder liner reduces further and, this small films diminish. The result will be scuffing of the contacting surfaces.

Figure 9 shows the oil film contour for the entire contact region. The island of minimum film thickness extends between the pressure peaks, when referring back to the pressure isobar plot of Fig. 4 .

The total deflection of the bodies is approximately $1.92 \mu \mathrm{m}$, accounting for more than 90 per cent of the gap size between them. The value of $\alpha p=0.03$ corroborates the insignificant increase in lubricant 


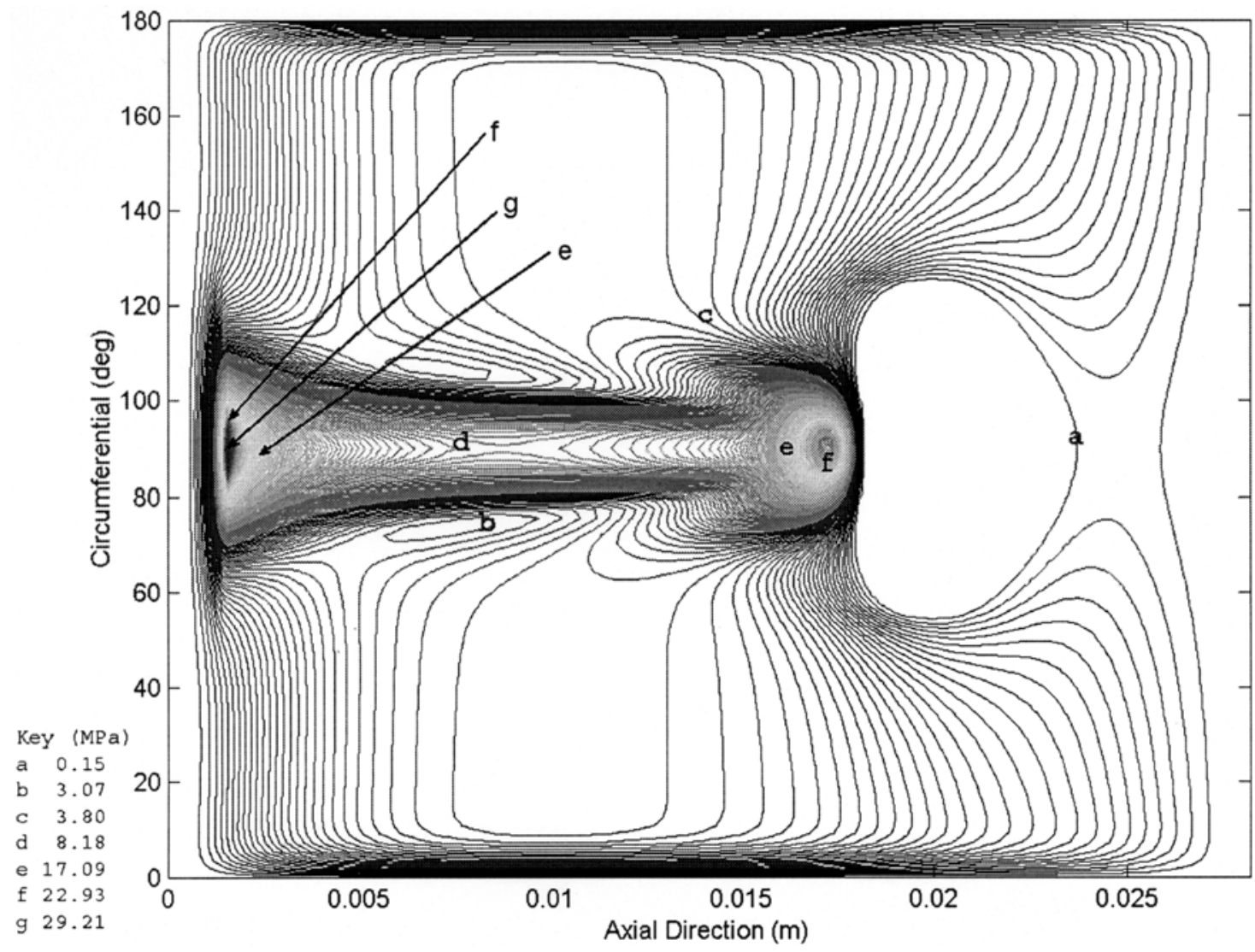

Fig. 4 Pressure isobar plot at combustion

viscosity at even the maximum value of pressures. Thus, the prevailing conditions are iso-viscous elastic. The lack of viscous action of the lubricant has been the source of concern, particularly at low speeds of entraining motion. At positions, other than the location of maximum combustion, TDC and BDC, the sliding velocity is quite high in this range of engines, and with appropriate piston skirt

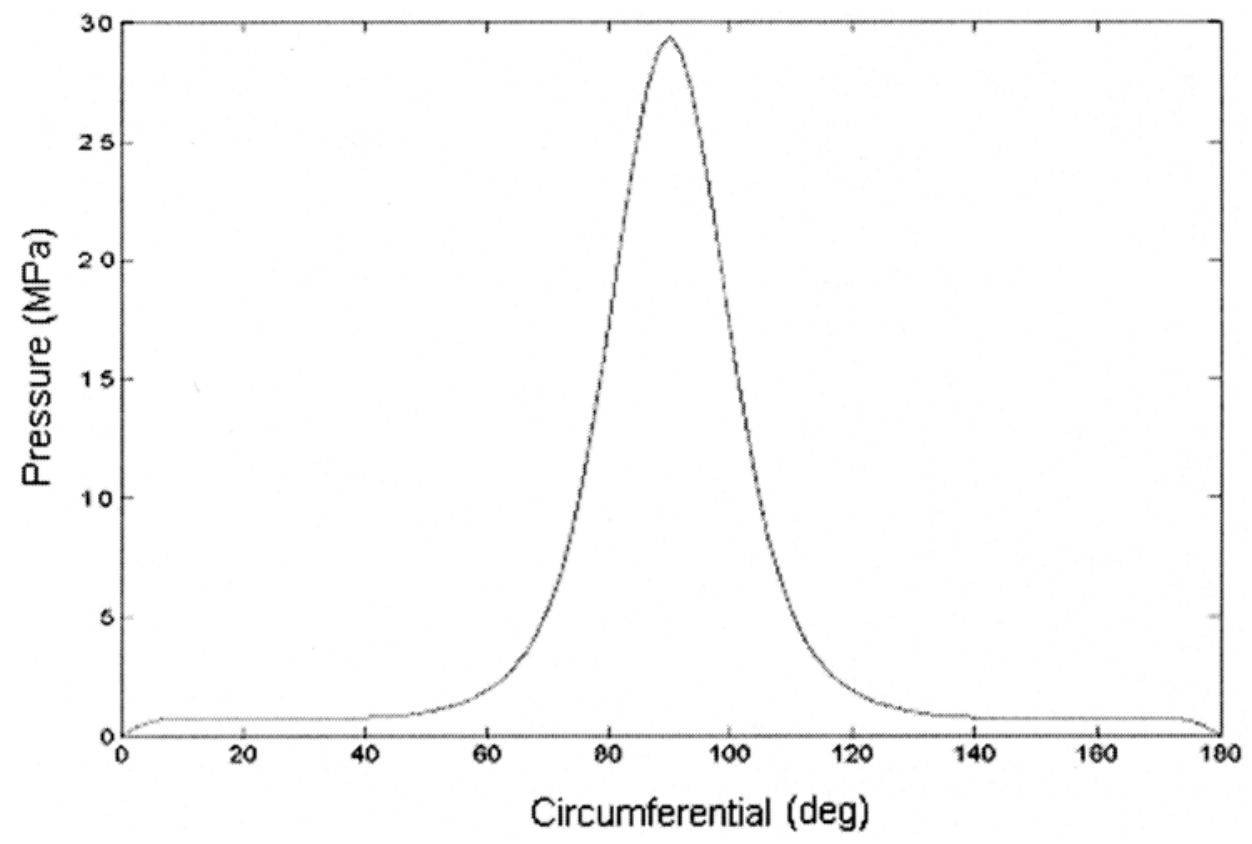

Fig. 5 Circumferential pressure distribution at inlet region 


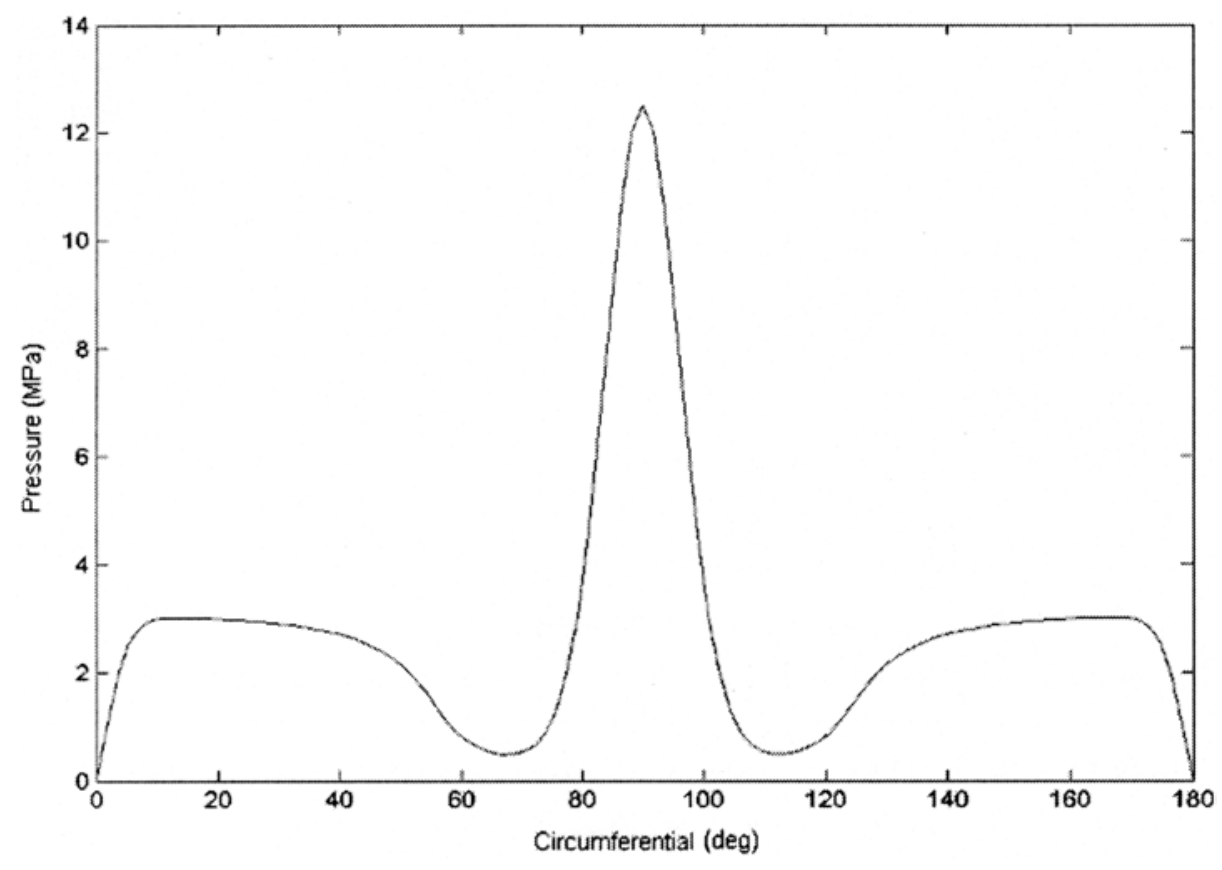

Fig. 6 Circumferential pressure distribution at outlet region

end profiles and a sufficient supply of lubricant, hydrodynamic films of sufficient thickness can be retained. Physics of motion of fluid in the aforementioned three locations must, therefore, be investigated in some detail (because in each case different mechanism of film formation is mainly responsible).
The flow through the contact at any location in the computation grid is obtained as

$$
q_{x}=-\frac{h^{3}}{12 \eta} \frac{\partial p}{\partial x}+\left(u_{1}+u_{2}\right) \frac{h}{2}
$$

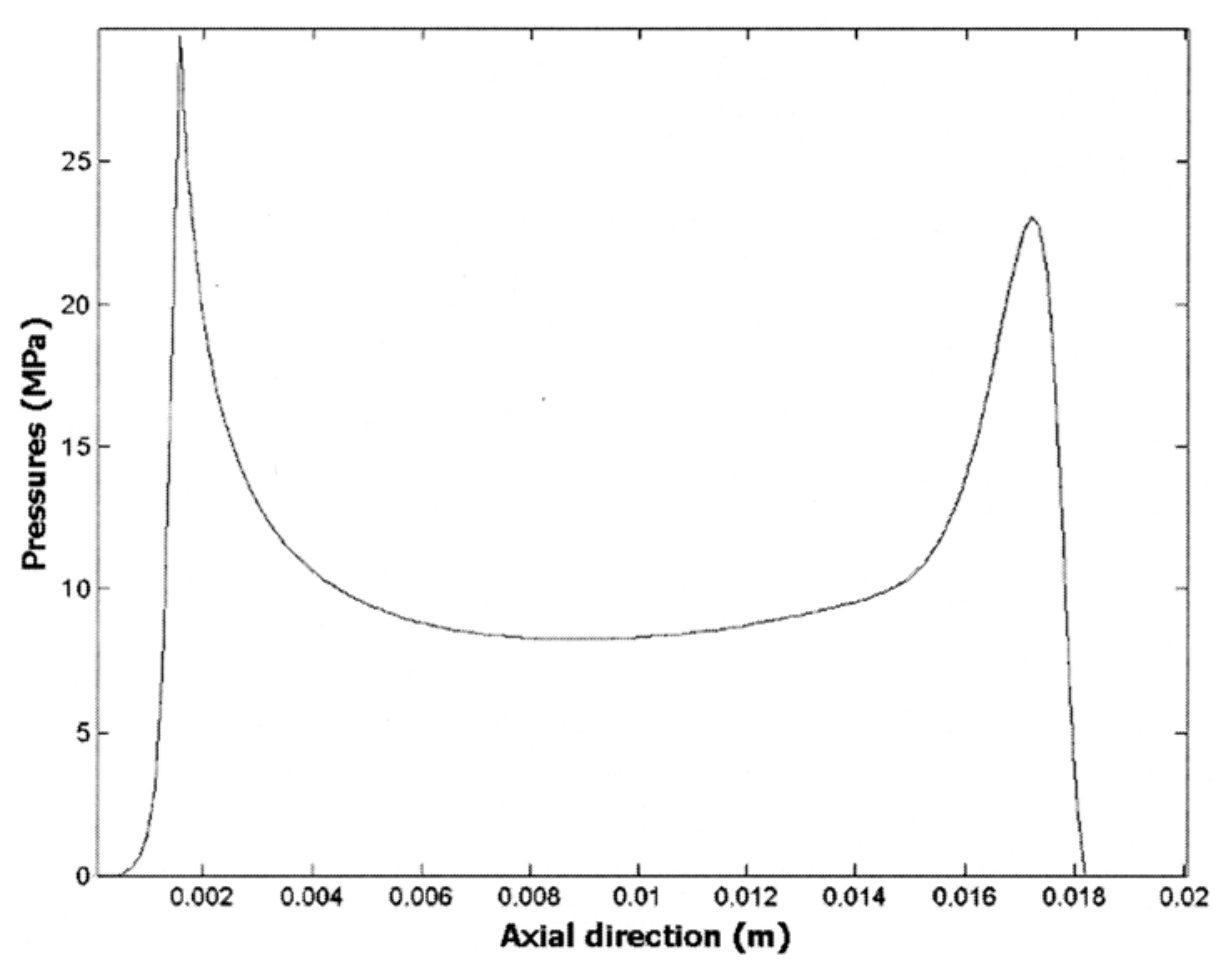

Fig. 7 Pressure distribution along axial direction at maximum combustion pressure 


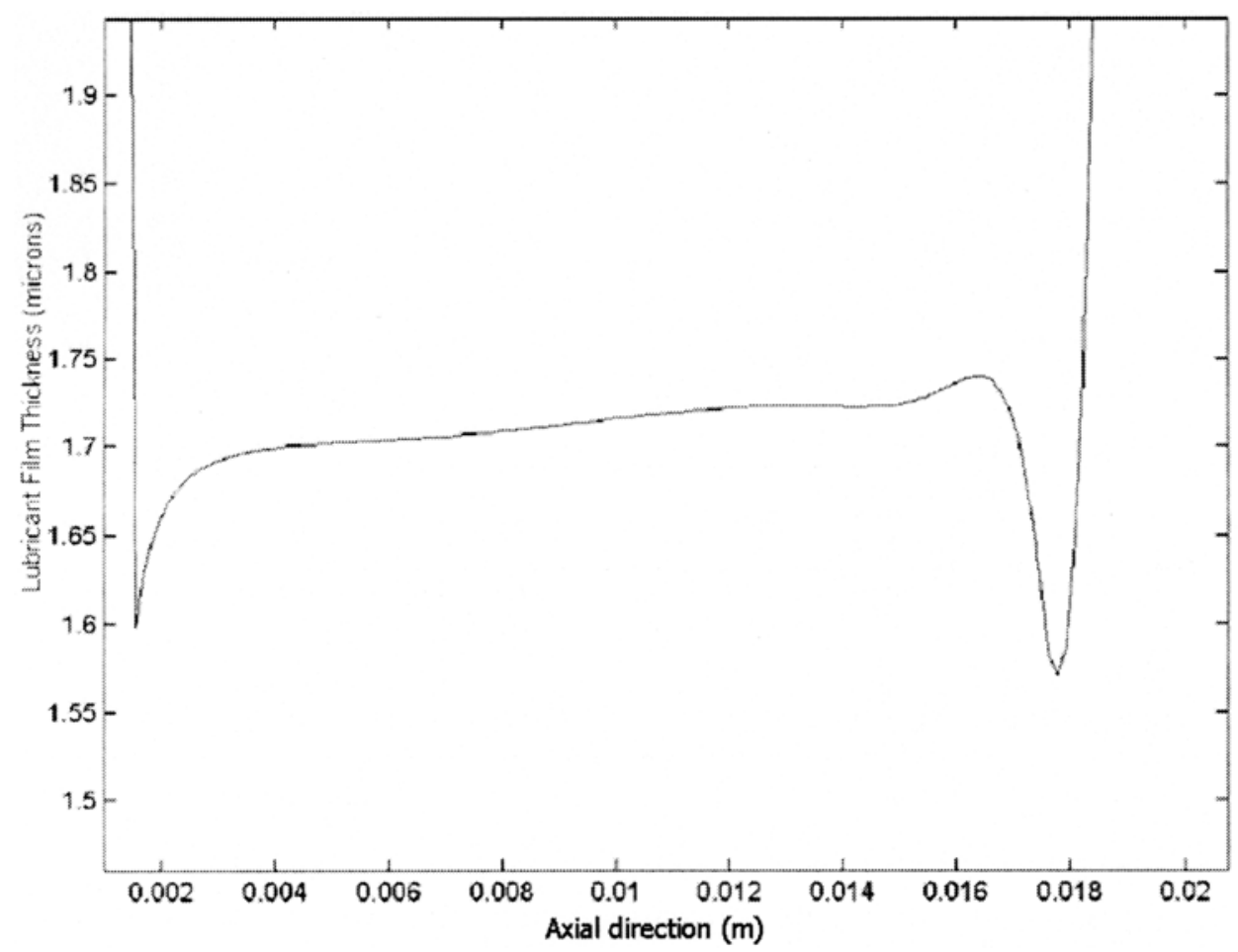

Fig. 8 Minimum lubricant film along axial direction at maximum combustion pressure

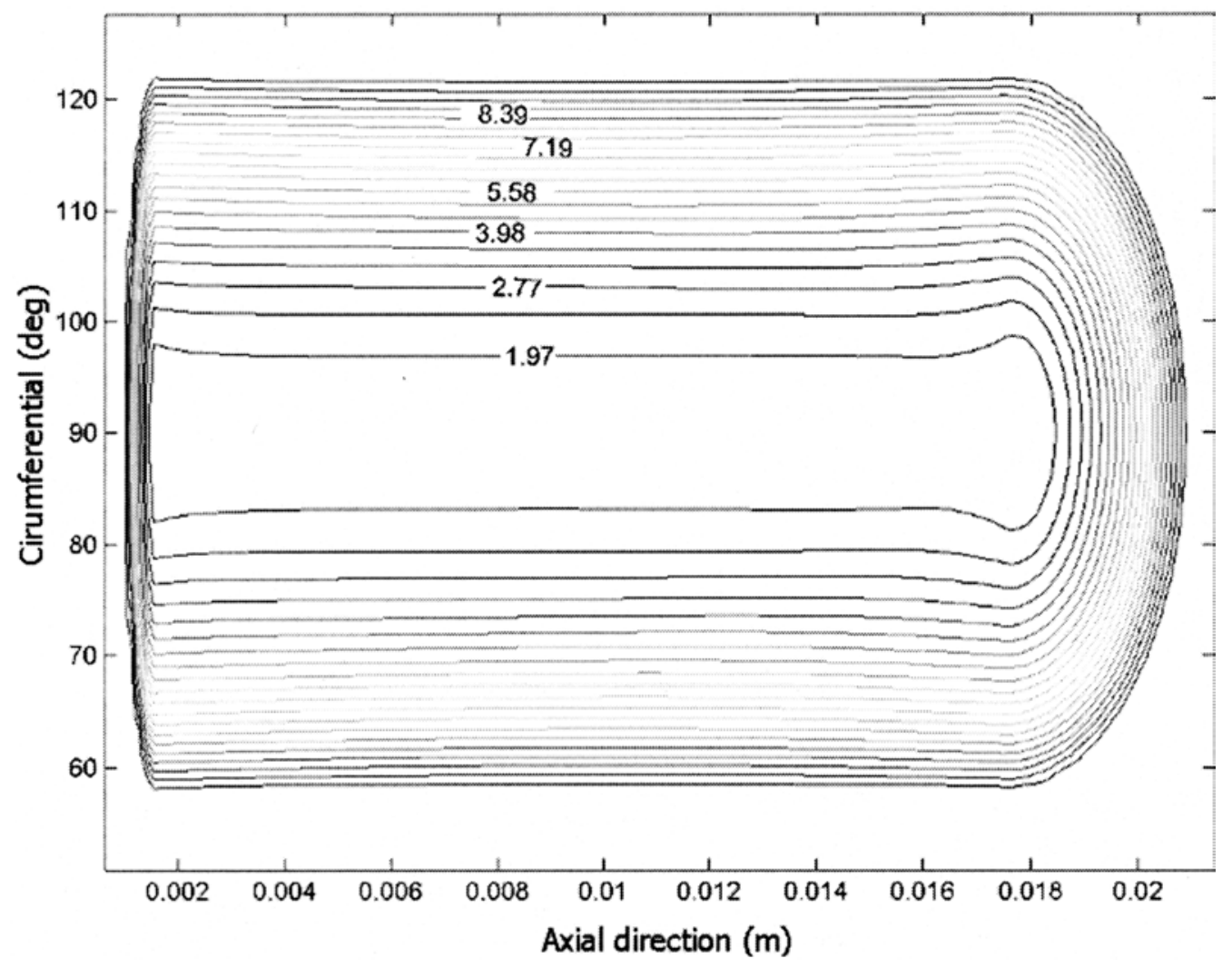

Fig. 9 Film contour plot for the entire contact region at combustion 
and

$$
q_{y}=-\frac{h^{3}}{12 \eta} \frac{\partial p}{\partial y}+\left(v_{1}+v_{2}\right) \frac{h}{2}
$$

Figures 10(a) and (b) show the inlet and outlet regions of the pressure isobars of Fig. 4, with the flow pattern superimposed as a vector plot. In Fig. 10(a), the inward flow is pulled into the contact by the entraining motion, but little flow ingresses into the region of high pressures, and subsequently into the actual contact. In fact, most of the flow goes onto the 'shoulders' of the contact beyond the high pressure region. Note that the length of the arrows indicates the magnitude of flow, which are much larger in the converging inlet gap than those in the high-pressure region. The same pattern is observed at the outlet region in reverse mode, where the outflow is much larger than those in the rear highpressure domain. Flows on the side-lobes (i.e. shoulders of the contact) are inward bound in the inlet region (Fig. 10(a)) and outward bound in the outlet region (Fig. 10(b)). This investigation shows, for the first time, the need for the introduction of lubricant-retaining surface features that have been arrived at in the motorsport industry largely by empirical intuition.

The transient nature of the lubricated contact alters the regime of lubrication from position to position [13]. Therefore, as already noted, geometrical and topographical features suited for a given location in the powerstroke may not necessarily be effective elsewhere. This means that surface modification work is neither necessary everywhere on the cylinder liner, nor in the same manner. The interaction of surface topography with geometrical features of mating pairs plays an important role, together with the lubricant rheology. As a consequence, there is a dearth of published data in this regard. This article provides some basic analysis with base-line modified topography to show its effectiveness at the same location (position of maximum combustion pressure).

The skirt is turned as per profile in Fig. 1(b). The bore is subjected to mechanical and thermal strain before final honing, so that when the piston is fitted into the bore under operating conditions, the surfaces conform to each other by a combination of bending of the skirt and thermal expansion. The surface finishes of the contiguous bodies render a root mean square value of approximately $0.3 \mu \mathrm{m}$. It has been already noted that the minimum film in some parts of the cycle in the case of the F1 engine piston skirt contact falls within the $1 \mu \mathrm{m}$ thickness. This means that asperity interactions can be expected at various locations, particular at BDC with no lubricant entrainment and a low contact force. Note that, even with entraining motion at the location of maximum pressure, contact deformation accounted for more than 95 per cent of the elastic film thickness. Therefore, it is axiomatic that surface features must be included at positions of low sliding velocity in order to trap a lubricant film.

Traditionally, it was thought that improved surface quality, thereby reducing the surface roughness of mating members would improve the situation. Therefore, super-finishing surface treatment methods have been used, such as lapping or honing. This is certainly true for large parts of the cycle, with high speed of entraining motion and predominant isoviscous rigid regime of lubrication. However, as the earlier analysis has shown lubricant entrapment in parts of the cycle, where cessation of entraining motion takes place or low piston velocities exist can account for a significant contribution to fluid film lubrication. Therefore, super-finishing together with inclusion of surface features on the piston skirt or cylinder liner or both is regarded as a possible solution to the reduction of friction and problem of wearing of piston liners.

The liner is often honed as described earlier, grooves are included on the mating piston skirt. The depth of the grooves is approximately $15 \mu \mathrm{m}$. They are introduced circumferentially with regular spacing of $250 \mu \mathrm{m}$. There is no particular scientific reason behind this configuration of grooves. Indeed, their introduction was not based upon any tribological study, prior to the work carried out in the current study.

To see the effect of the introduction of these surface features the profile of the piston liner is modified to include the introduced undulations. The methodology employed for the tribological study remains unchanged. Therefore, the included features are also subjected to deformation of the contiguous surfaces, analogous to a micro-elastohydrodynamic analysis, with the difference that other surface roughness of the contiguous bodies is not taken into account, and that the generated pressures (as can be seen from the analyses described thus far) do not promote viscous-elastic (elastohydrodynamic) conditions, rather iso-viscous elastic regime of lubrication for most of the loaded part of the cycle. The analysis is carried out for the same location (i.e. at the position of maximum combustion pressure).

Figure 11 shows the three-dimensional pressure distribution for this case. This result is directly comparable with the same condition, but without the introduced surface features, depicted by Fig. 3. Two interesting initial observations can be made. First, the generated pressures are affected by the introduction of these surface grooves. Second, the comparison with Fig. 4 shows increased edge pressure 


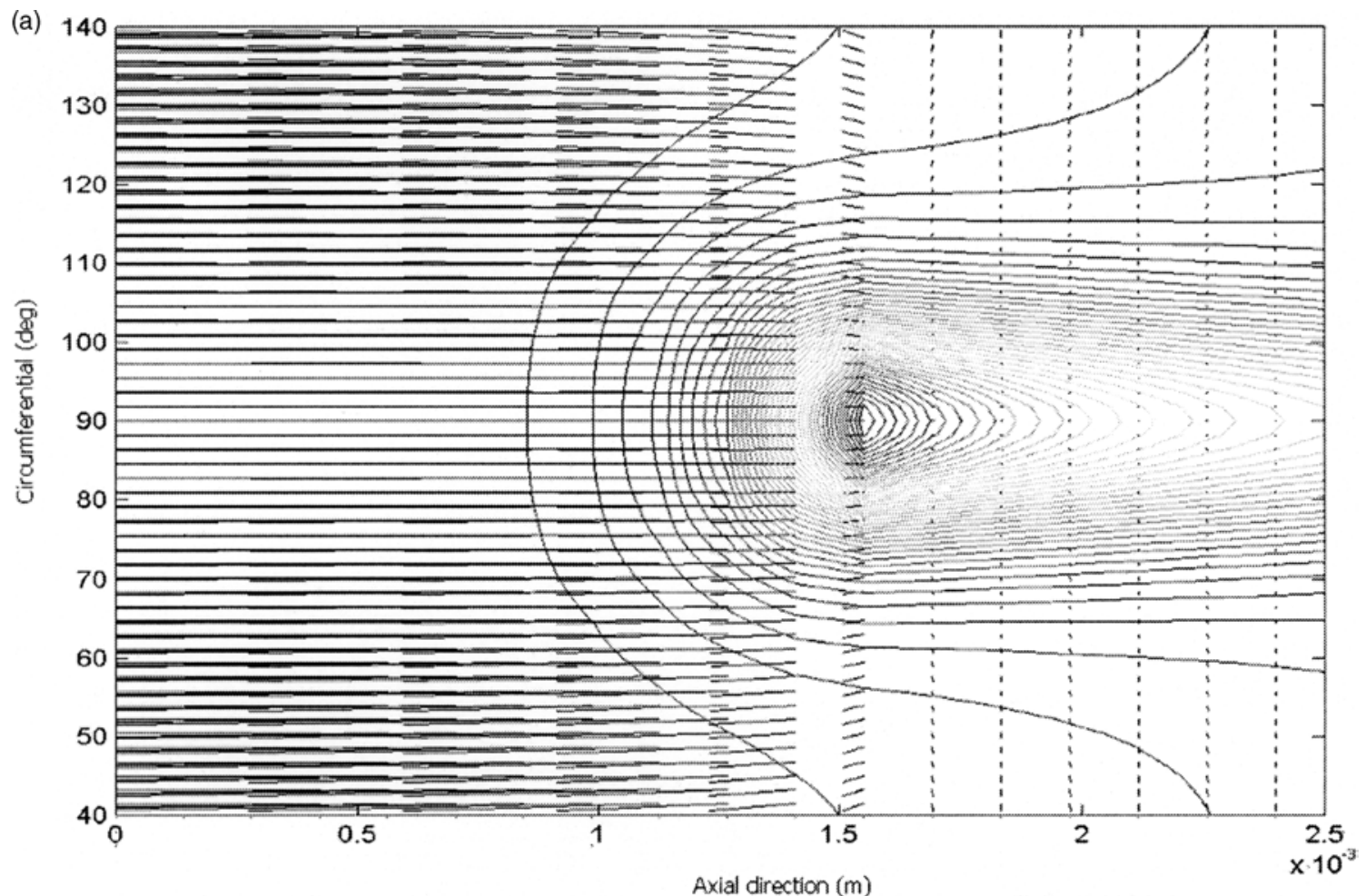

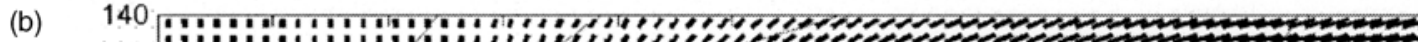

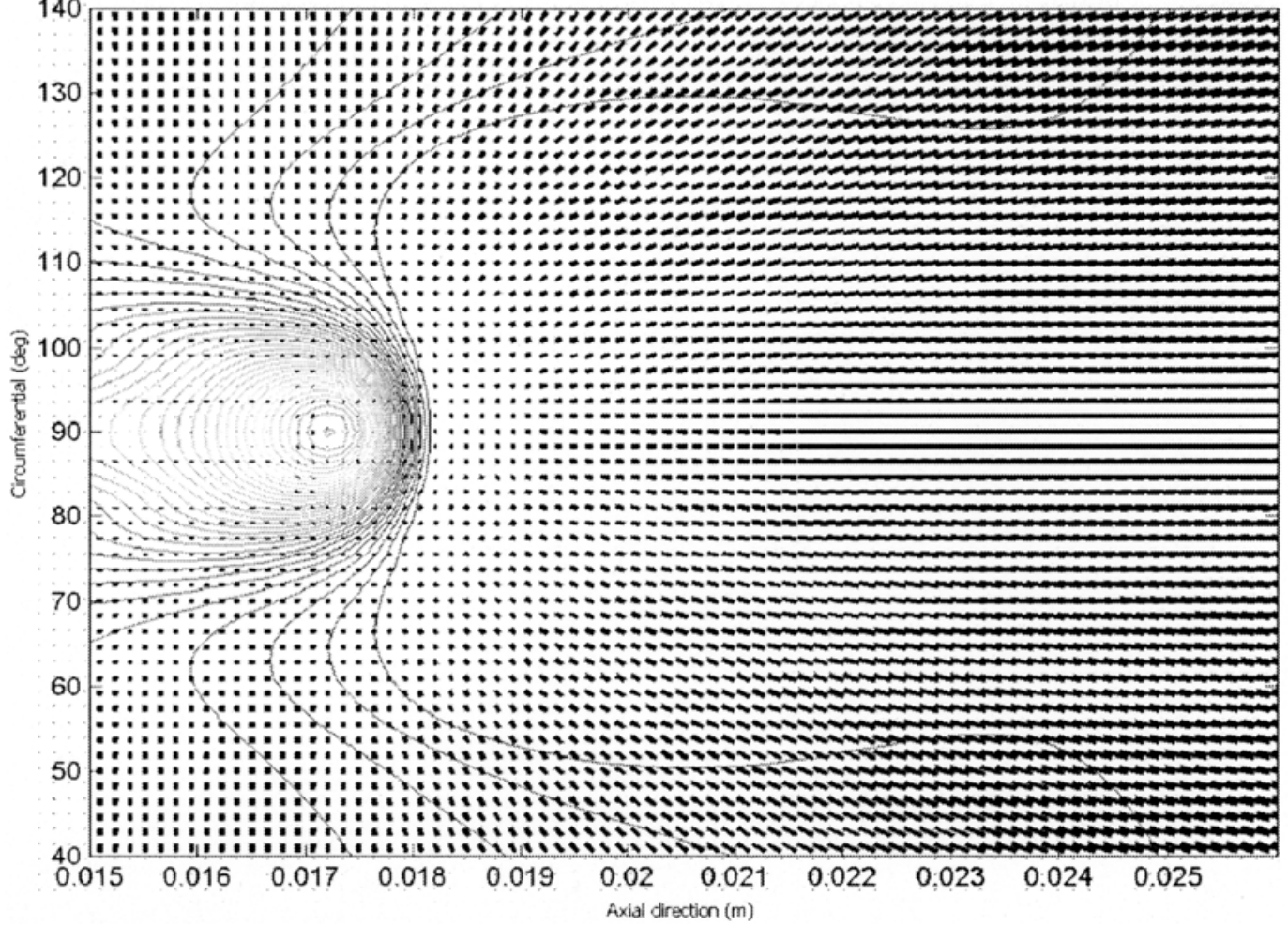

Fig. 10 (a) Magnification of flow pattern superimposed on pressure isobar plot at the inlet region (b) Magnification of flow pattern superimposed on pressure isobar plot at the outlet region

magnitudes, reduced central region pressures and a reversal in the disposition of pressure spike magnitudes. In other words, the pressure spike at the contact outlet (to the right-hand side of the figure) is larger in magnitude than that at the inlet, opposite to the behaviour noted in Fig. 4. The axial pressure distribution along the piston skirt-to cylinder liner is better observed from Fig. 12, corresponding to 


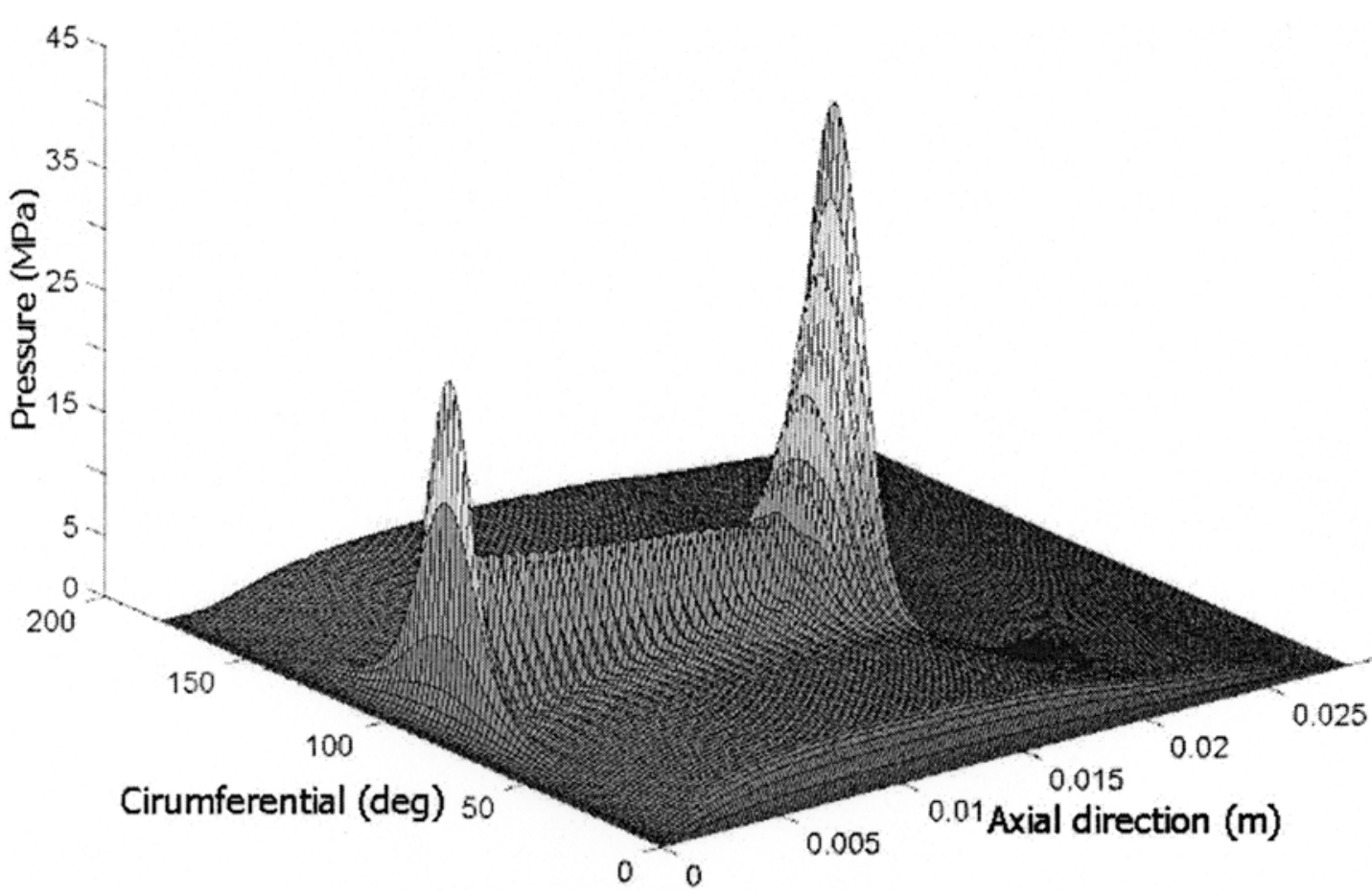

Fig. 11 Three-dimensional pressure distribution plot for a piston with surface modification during combustion (entraining direction from left to right along the axial direction)

the mid-circumferential position with the minimum gap. The induced pressure spikes owing to sharp edges of the grooves are clearly visible. Because the groove depths are reasonably deep $(15 \mu \mathrm{m})$ when compared with the insignificant contact deformation of the cylinder liner at $1.92 \mu \mathrm{m}$, the pressure vanishes over each groove, giving rise to a rather strange looking distribution.

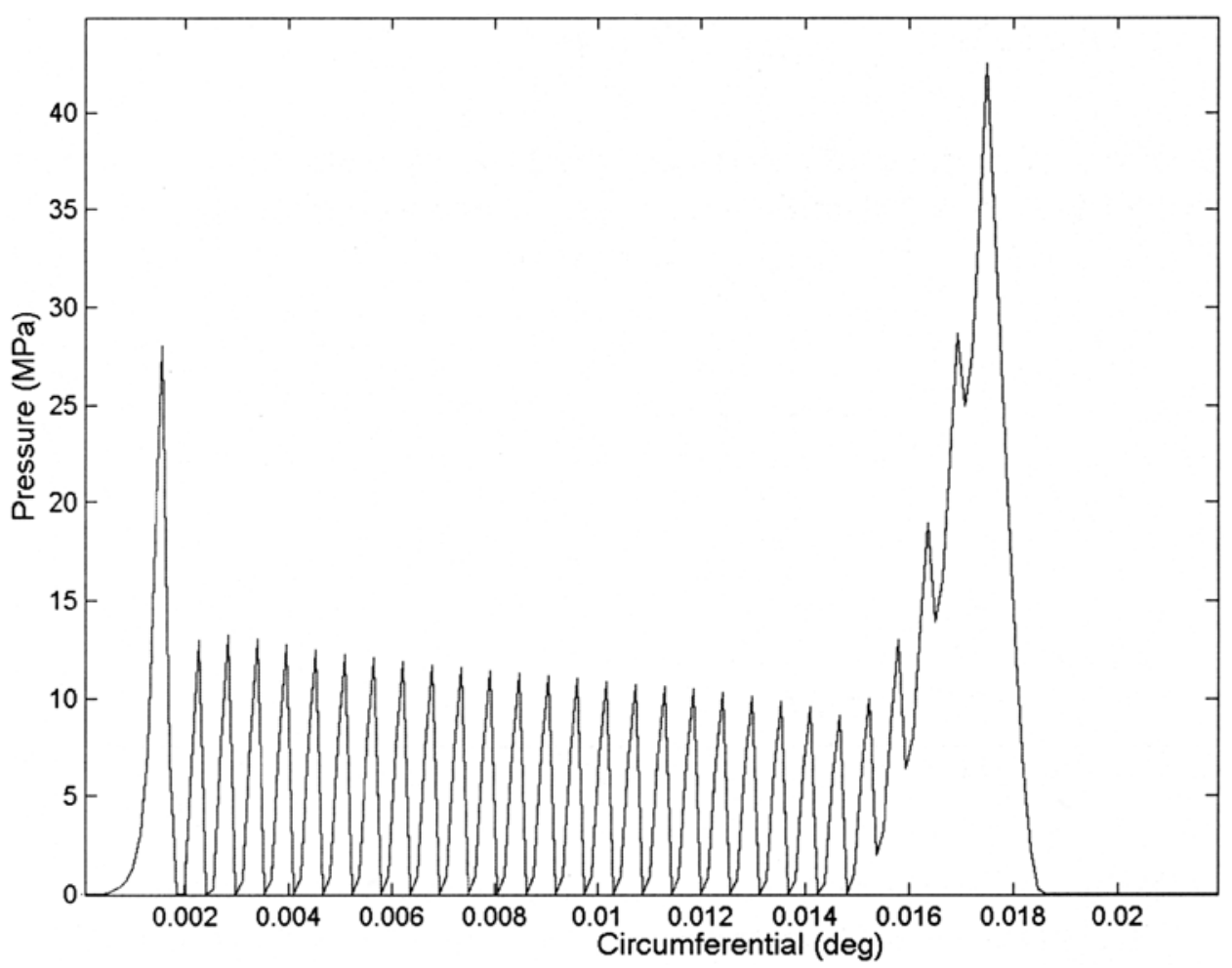

Fig. 12 Axial plot along the maximum pressure for a piston with surface modification during combustion 


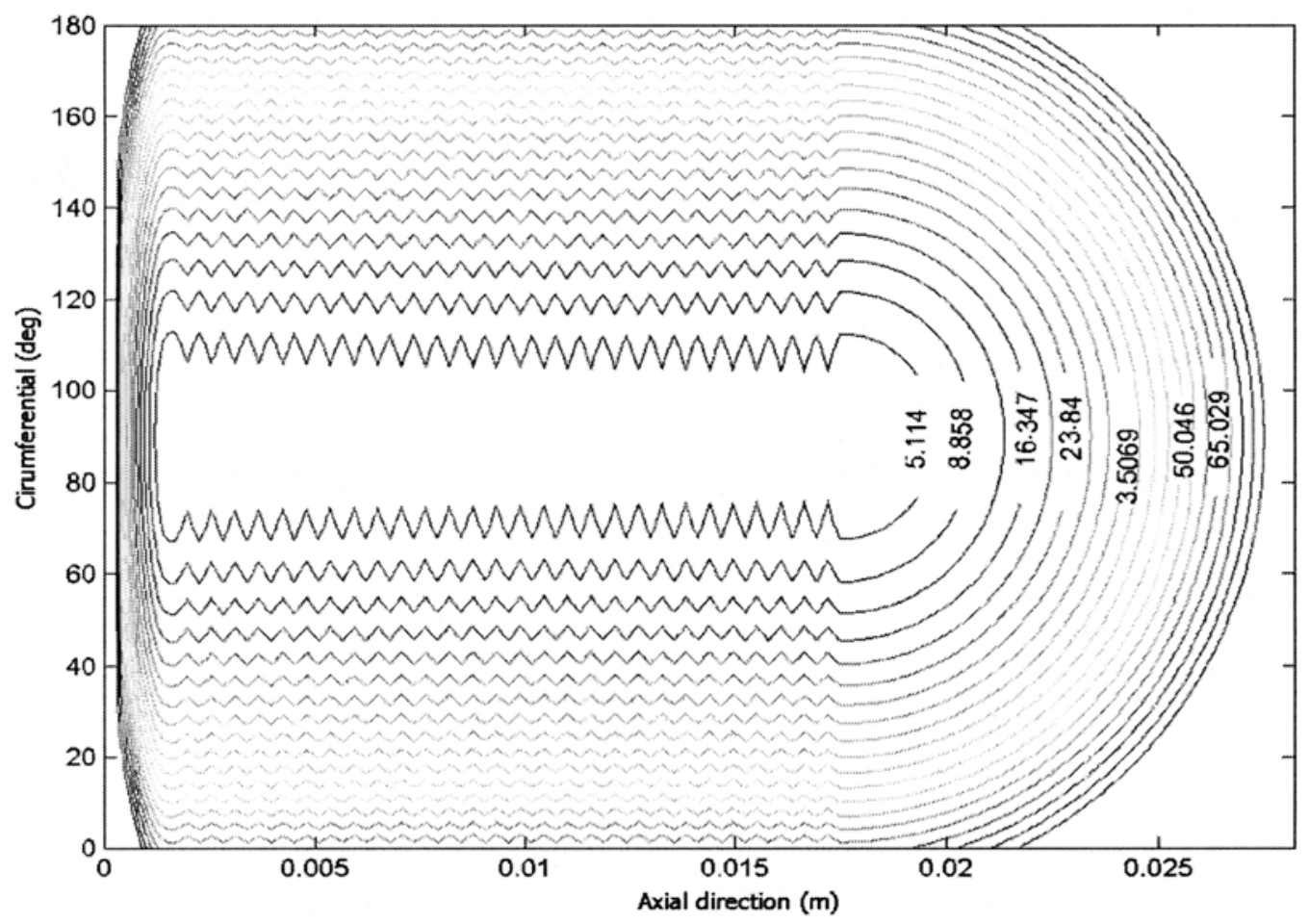

Fig. 13 Lubricant film contour $(\mu \mathrm{m})$ plot for a piston with surface modification during combustion

Finally, the corresponding oil film contour in Fig. 13 shows that the minimum film thickness is increased from $1.97 \mu \mathrm{m}$ (in the unmodified case of Fig. 9) to $5.1 \mu \mathrm{m}$, which for a composite surface roughness of $0.3 \mu \mathrm{m}$ for the contiguous surfaces in contact shifts the ratio $\lambda=h_{\min } / \sigma$ from approximately a value of unity (indicating the demarcation line between mixed and boundary regimes of lubrication in a typical Stribeck curve) to 16.7 (well inside the hydrodynamic regime of lubrication and tending to full fluid film separation).

\section{CONCLUSION}

It has been shown that even under most severe tribological conditions encountered at high contact loads, and relatively low speed of entraining motion (for a short stroke piston motion) and misaligned contact conditions, very limited viscous action of fluid is achieved. Consequently, even with the use of super-finished mating surfaces, adverse regimes of lubrication; mixed or boundary dominate in a significant part of the operating cycle. This leads to unacceptable frictional losses and scuffing of contiguous solid surfaces in contact. It has also been shown that abrupt changes in the axial profile of the piston, even with form relieving does not lessen the pressure spikes at the leading and trailing edges of the contact, which inhibit the flow of lubricant into the contact domain. Thus, significant surface modification has to be carried out to lessen the effect of these adverse conditions. The detailed numerical analysis explains the observed improved performance of the high speed racing engines with the use of these advance cylinder liners.

Future investigations and developments should comprise further convergence between numerical analysis and cylinder liner and piston modification features and optimization of this for given leading and trailing axial relief radii.

\section{REFERENCES}

1 Sato, O., Takiguchi, M., Aihara, T., and Seki, Y. Improvement of piston lubrication in a diesel engine by means of cylinder surface roughness. SAE 2004-01-0604.

2 Taylor, R. I. Lubrication, tribology and motorsport. SAE 2002-01-3355.

3 Knoll, G. D. and Peeken, H. J. Hydrodynamic lubrication of piston skirts. Trans. ASME, 1982, 104, 504-509.

4 Li, D. F., Rhode, S. M., and Ezzat, H. A. An automotive piston lubrication model. ASLE Trans., 1982, 26, 151-160.

5 Oh, K. P., Li, C. H., and Goenka, P. K. Elastohydrodynamic lubrication of piston skirts. ASME J. Tribol., 1987, 109, 356-362.

6 Offner, G. and Priebsch, H. H. Elastic body contact simulation for predicting piston slap induced noise in 
an IC engine. In Multi-body dynamics: monitoring and simulation techniques-II (Eds H. Rahnejat and R. Whalley), 2000 (Mechanical Engineering Publications, Bury St Edmunds and London), ISBN 1860582533.

7 Balakrishnan, S. and Rahnejat, H. Transient elastohydrodynamic lubrication of piston skirt to cylinder liner under combined reciprocating and slapping motions. Proceedings of the Third AIMETA International Tribology Conference, Salerno, Italy, 2002.

8 Barus, C. Isothermal, isopiestics and isometrics relative to viscosity. Am. J. Sci., 1893, 45, 87.

9 Dowson, D. and Higginson, G. R. The effect of material properties on the lubrication of elastic rollers. J. Mech. Eng. Sci., 1960, 2, 188.

10 Johns, P. M. and Gohar, R. Roller bearings under radial and eccentric loads. Tribol. Int., 1981, 14, 131.

11 Kushwaha, M. and Rahnejat, H. Transient elastohydrodynamic lubrication of finite line conjunction of cam to follower concentrated contact. J. Phys. D: Appl. Phys., 2002, 35(21), 2872-2890.

12 Rahnejat, H. and Gohar, R. Design of profiled taper roller bearings. Tribol. Int., 1979, 11, 269-275.

13 Balakrishnan, S. and Rahnejat, H. Isothermal transient analysis of piston skirt-to-cylinder wall contacts under combined axial, lateral and tilting motion. J. Phys. D: Appl. Phys., 2005, 38(5), 787-799.

\section{APPENDIX}

\section{Notation}

$\tilde{a}, \tilde{b}$

computational domain

$c$

$\bar{c}$
$E^{\prime}$

$F^{\mathrm{R}}$

$\frac{h}{h}$

$i, j$

$J$

$p$

$q_{x}, q_{y}$

$r_{\mathrm{b}}, r_{\mathrm{p}}$

$S$

$t$

$u_{1}, u_{2}$

$u_{\mathrm{AV}}$

$v_{1}, v_{2}$

W

$x, y$

$\alpha$

$\beta$

$\delta$

$\Delta p$

$\eta$

$\eta_{0}$

$\bar{\rho}$

$\rho$

$\Omega$

$\xi$ effective modulus of elasticity of liner and piston

residual function of the discretized Reynolds equation

film shape

$h /\left(r_{\mathrm{b}}-r_{\mathrm{p}}\right)$

computation nodal points

Jacobian matrix

generated lubricant pressure

dimensionless pressure, $\left(p / E^{\prime}\right)$

flow in $x$ - and $y$-direction respectively

radii of bore and piston, respectively

surface profile

time

velocities of piston and liner in

$x$-direction, respectively

speed of entraining motion

velocities of piston and liner in $y$-direction, respectively

applied load

Cartesian coordinates

pressure-viscosity of lubricant

tilt angle of piston

elastic deformation

pressure residual

dynamic viscosity at any pressure

isothermal absolute atmospheric

dynamic viscosity

non-dimensional density

density

under-relaxation factor

film damping parameter 